\title{
Synthesis of Phenolic-Based Resist Materials for Photolithography
}

\author{
SUTIKNO*, MUHAMMAD LUKMAN HAKIM and SUGIANTO \\ Physics Department, Faculty of Mathematics and Natural Sciences, Semarang State University (Unnes), \\ Sekaran Street, Gunungpati Semarang, 50229, Indonesia. \\ *Corresponding author E-mail: smadnasri@yahoo.com \\ http://dx.doi.org/10.13005/ojc/320117
}

(Received: December 19, 2015; Accepted: February 21, 2016)

\begin{abstract}
Phenol-based photoresist for photolithography application is successfully developed in this research namely by mixing phenolic resin with ethanol solvent and sodium acetate 3-hydrate 30\% of phenolic resin mass. Novolac phenolic resin is made by mixing formaldehyde and phenol in mol ratio 2,8:1 catalyzed using $\mathrm{NaOH}$. Phenolic resin is made at heating temperature of $85^{\circ} \mathrm{C}$ and stirring rotation speed of $1000 \mathrm{rpm}$. Photoresist thin film is spincoated on the glass substrate and prebaked on the hotplate at $95^{\circ} \mathrm{C}$ for $60 \mathrm{~s}$. The research result shows that microstructures of resist films which are manufactured of resol phenolic resin seem more homogeneous than that of novolac phenolic resin. The maximum absorbance is in the wavelength range of $380-500 \mathrm{~nm}$, its density and viscosity are $1,41 \mathrm{~g} / \mathrm{ml}$ and 198 centipoise, respectively.
\end{abstract}

Key words: Novolac, Phenolic, Photoresist, Photolitography, Spincoating.

\section{INTRODUCTION}

The Indonesian goverment attempts in developing industries have been still facing no warranty of raw material supplies. Especially for microelectronic industry, the supply sustainability of raw materials are no assurrance so that it becomes a serious problem for the local microelectronic industry development. The crucial step here is how to ensure the avaibility of raw materials for microelectronics industries. The potency of Indonesia natural resources poses the second rank after Brazil either for biodiversity or minerals resources. Many organic materials which can be converted into raw materials for microelectronic industry, for example natural phenol is available to manufacture photoresist which is applicable for photolihography.

In recent years, the synthesis of solar sensitive polymer has been developed for photolithography. Some polymers sensitive to light are applied in microlithography, printing material, liquid crystal and non-linear optical. These polymer properties are good solubility, good film forming capability, high photosensitivity, un-soluble in solvent after crosslinking, high thermal stability and resistance to plasma and etching agents ${ }^{1}$. 
The resist synthesis for microlithography is necessary developed, because the lithography process is a key to produce electrical circuits in small dimension and to shrink component size in microlectronic device. The decrease of device size increases it's capability and decrease the production $\operatorname{cost}^{2}$.

To increase density of integrated circuit (IC), feature size of patterns made using lithography will be smaller. In recent years, organic materials are considered very promising to manufacture photoresist because they have good photothermal sensitivity, long lifetime, processable in vacuum, clear border line between exposed and un-exposed area, light molecule weight and stronger chemical bonding ${ }^{3}$.

The photoresist is multicomponent system which consist of photoresist polymer, photoacid generator (PAG), and aditive ${ }^{4}$. It is an important chemical in semiconductor processing, liquid crystal display (LCD) and printing process 5 . In the manufacturing process of semiconductor device, photoresist is used as mask ${ }^{6}$. The photoresist composite is also developed for electrode photopatterning which available for biochip?

One of most important polymers is formaldehyde phenol resin polymer. Formaldehyde phenol resin is synthetic polymer of reaction result of phenol and formaldehyde. The phenolic resin is main material to produce circuit patterns ${ }^{8}$. The formaldehyde phenol is the first synthetic resin which used in commercial industries either plastic or paint industry. The condensation reaction of phenolic on different two conditions includes resol and novolac ${ }^{9}$. The polymer which often used to manufacture photoresist is novolac resin namely formaldehyde phenolic polymer with acid as catalyst ${ }^{10}$.

The photoresist performance in microplithography depends on the used polymer. Many reasearchs are focused in investigating polymer microstructuresto achieve high resolution ${ }^{10}$. The polymer also functions to control solution viscosity. Another function is to support film forming and to increase mechanical properties of resulted photoresist liquid ${ }^{11}$. The photoresist appplications in microelectronic industry range very wide area. The viscosity of polymer can be optimised by variating mol fraction of formaldehyde and phenol and reaction duration. The different polymer viscosity in manufacturing photoresist will produce photoresist with different viscosities, so that in the film forming will lead to different microstructures and the different absorbances.

\section{MATERIALS AND METHOD}

The used equipments include Ohauss balance, pipette, heated magnetic stirrer, beaker glass, measuring glass, thermometer, spincoater, scopeman digital CCD microscope MS-804, spectrophotometer (ocean optic Vis-NIR USB 4000), and brookfield dial viscometer.The materials used in this research consist of preparate glass, phenol $\left(\mathrm{C}_{6} \mathrm{H}_{5} \mathrm{OH}\right)$, formaldehyde $\left(\mathrm{CH}_{2} \mathrm{O}\right)$, 4-tert-butylphenol $\left(\mathrm{C}_{10} \mathrm{H}_{14} \mathrm{O}\right)$, natrium hydroxide $(\mathrm{NaOH})$, acid sulphate $\left(\mathrm{H}_{2} \mathrm{SO}_{4}\right)$, ethanol $\left(\mathrm{C}_{2} \mathrm{H}_{5} \mathrm{OH}\right)$, and sodium acetate trihydrate $\left(\mathrm{Na}-\mathrm{C}_{2}-\mathrm{H}_{3}-\mathrm{O}_{2} \cdot 3 \mathrm{H}_{2} \mathrm{O}\right)$.

To make resin phenolic resol polymer, phenol $(0,8 \mathrm{~mol}$ phenol, $0,2 \mathrm{~mol}$ and $0,2 \mathrm{~mol} 4$-tertbutylphenol) and 2,8 mol formaldehyde are mixed. On the other hand, resin phenolic novolac is made in two composition, first one contains phenol $(0,8$ mol phenol, 0,2 mol 4-tert-butylphenol) and 0,8 mol formaldehyde, and another one contains phenol $(0,8$ mol phenol, 0,2 mol 4-tert-butylphenol) and 0,75 mol formaldehyde. To make resin phenolic novolac and resin phenolic resol were used sulphate acid and natrium hidroxyde, respectively, by through mixing process using heated magnetic stirrer at speed of $1000 \mathrm{rpm}$ and temperature of $85^{\circ} \mathrm{C}$.

The photoresist is made through mixing of resin phenolic polymer with ethanol amount of $20 \%$ of mass total of polymer and sodium acetate 3-hydrate (photosensitive material) amount of 30\% of resin phenolic mass using heated magnetic stirrer at constant speed $100 \mathrm{rpm}$ up to it's temperature achieved $85^{\circ} \mathrm{C}$. The photoresist thin films were spincoated on preparate glasses. The photoresist liquid was dropped on the preparate glasses at constant speed for 60 seconds.

The microstructures of photoresist thin films were observed using scopeman digital CCD 
microscope MS-804 and their absorbances were measured in the wavelength range of $350-1000 \mathrm{~nm}$ using spectrometer (ocean optic Vis-NIR USB 4000). The viscosity of photoresist liquid is measured using brookfield dial viscometer and it's densities were measured using ratio of mass and volume for each sample.

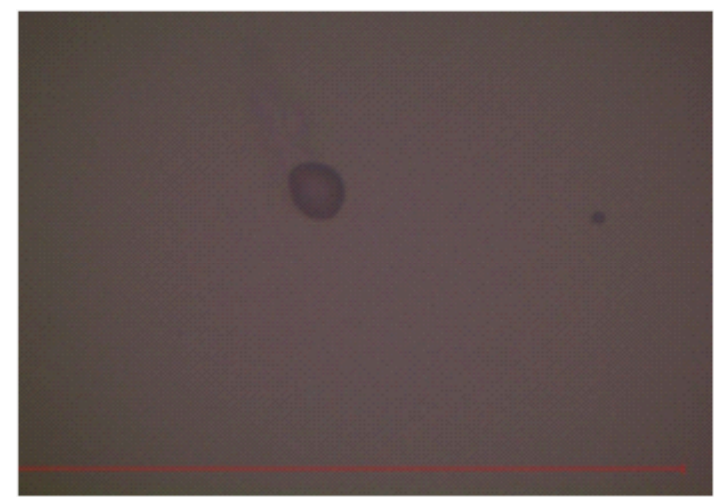

Fig. 1: Microstructure of photoresist thin film with mol ratio of formaldehyde and phenol equals to 2,8 and 1 and catalyst reaction during 35 minutes

\section{RESULTS AND DISCUSSION}

In Figure 1, surface of photoresist thin film seems homogeneous, nevertheless there has been seem a dot in that surface which shows an impurity. Figure 2 is taken in magnification of 2400x. In general, the surface microstructures of resin phenolic resol polymer show smooth and homogeneous surfaces.

The photoresist thin films of resin phenolic novolac have different surface microstructures as shown in Figure 3. Figure $3 a$ appears that the resulted photoresist thin films have rough surface structure and inhomogeneous. The same condition is found in Figure $3 \mathrm{~b}$. The catalyst used here is sulphate acid. The surface structure of Figure 3 looks more homogeneous and smoother than those of Figure $3 a$ and $3 \mathrm{~b}$. As the durationof the catalyst (sulphate acid) reaction increases in making photoresist novolac polymer the homogenity increases as well.

Figure 4 a looks that the surface structure of photoresist thin film is rough and inhomogeneous. Figure $4 \mathrm{~b}$ is more homogeneous and smoother than that of Figure 4a. Figure 4c has smoother surface structure and more homogeneous than those of
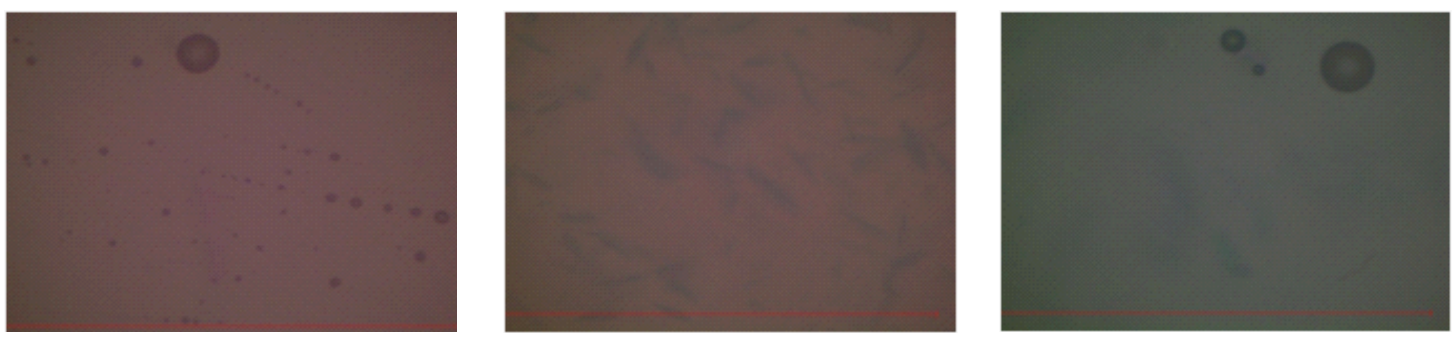

Fig. 2: The surface structure of polymer photoresist thin film with mol ratio of formaldehyde and phenol equals to 2,8 and 1 in catalyst reaction for: (a) 37,5 (b) 40 (c) 42,5 minutes
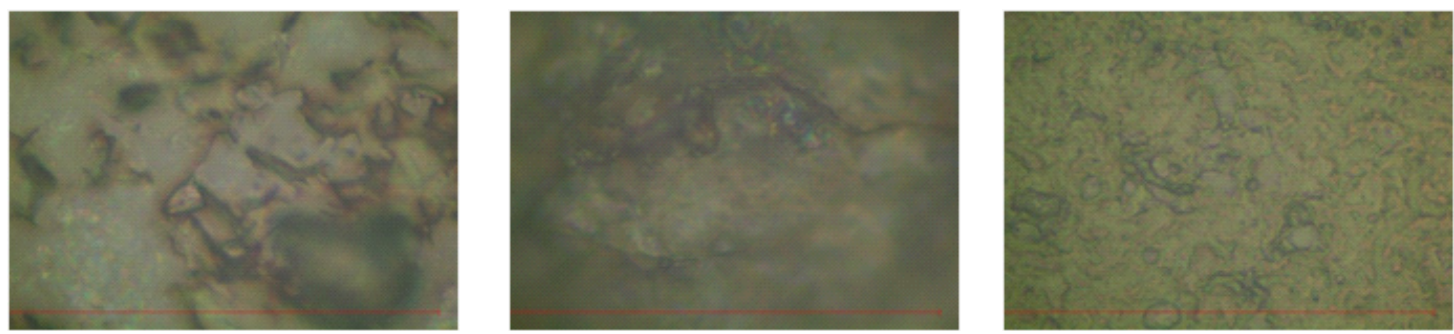

Fig. 3: The surface microstructures of polymer photoresist thin films with mol ratio of formaldehyde and phenol equals to $0,8: 1$ in catalyst reaction for: (a) 37,5 (b) 40 (c) 42,5 minutes 

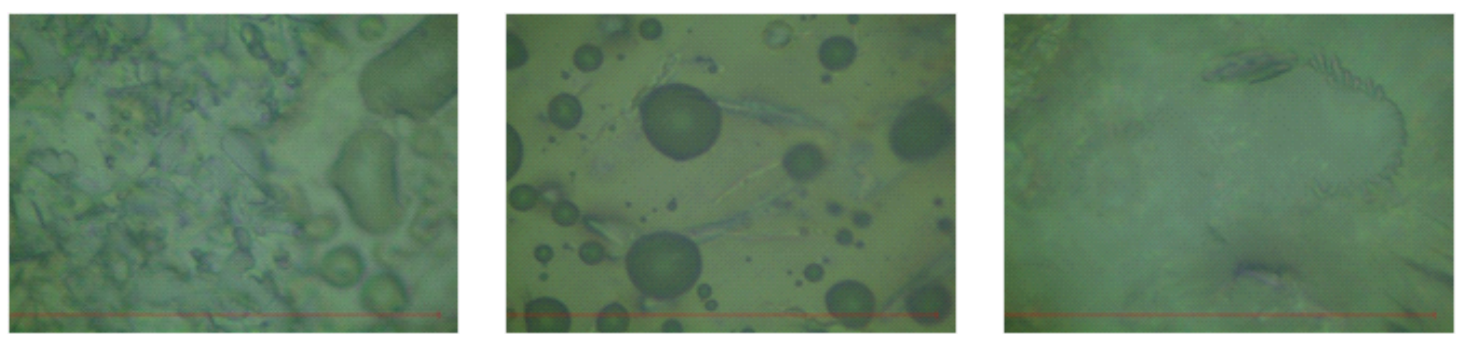

Fig. 4: The surface structures of photoresist thin films with mol ratio of formaldehyde and phenol equals to $0,75: 1$ in the catalyst reactions for: (a) 37,5 (b) 40 and (c) 42,5 minutes

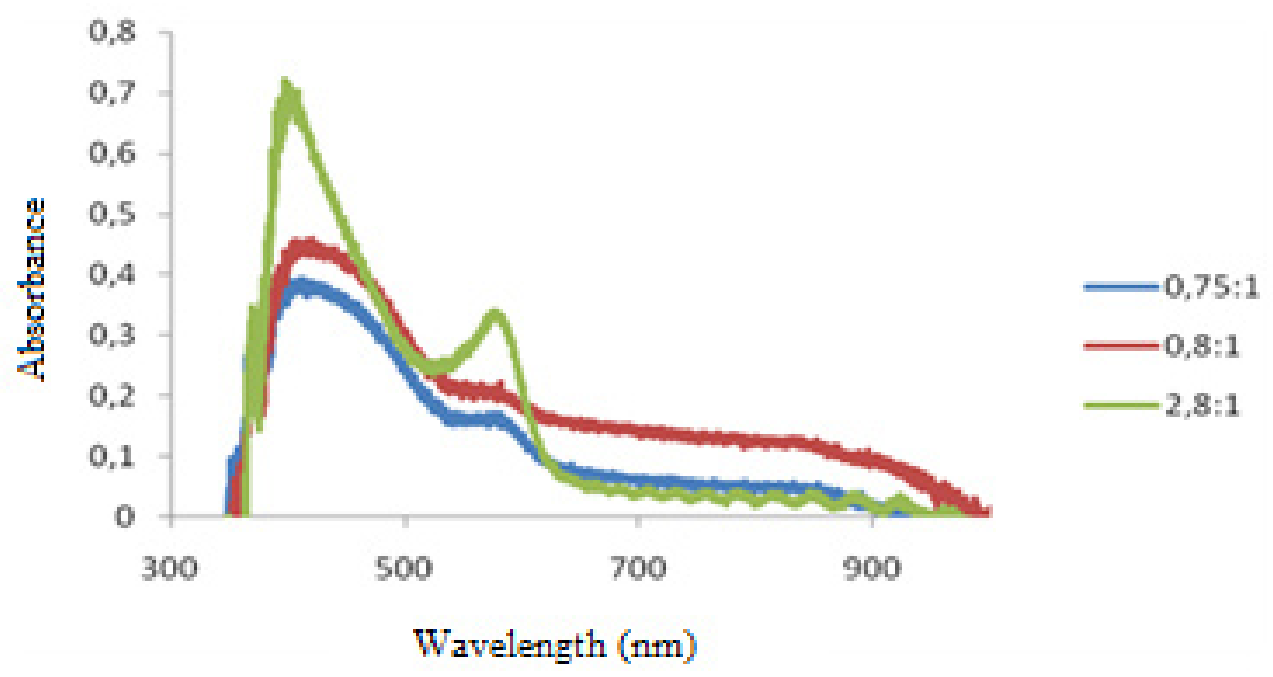

Fig. 5: Graph of wavelengths and absorbances of polymer photoresist thin films with mol ratios of formaldehyde and phenol equal to $(0,75: 1)$ and $(2,8: 1)$ in catalyst reaction for 37,5 minutes

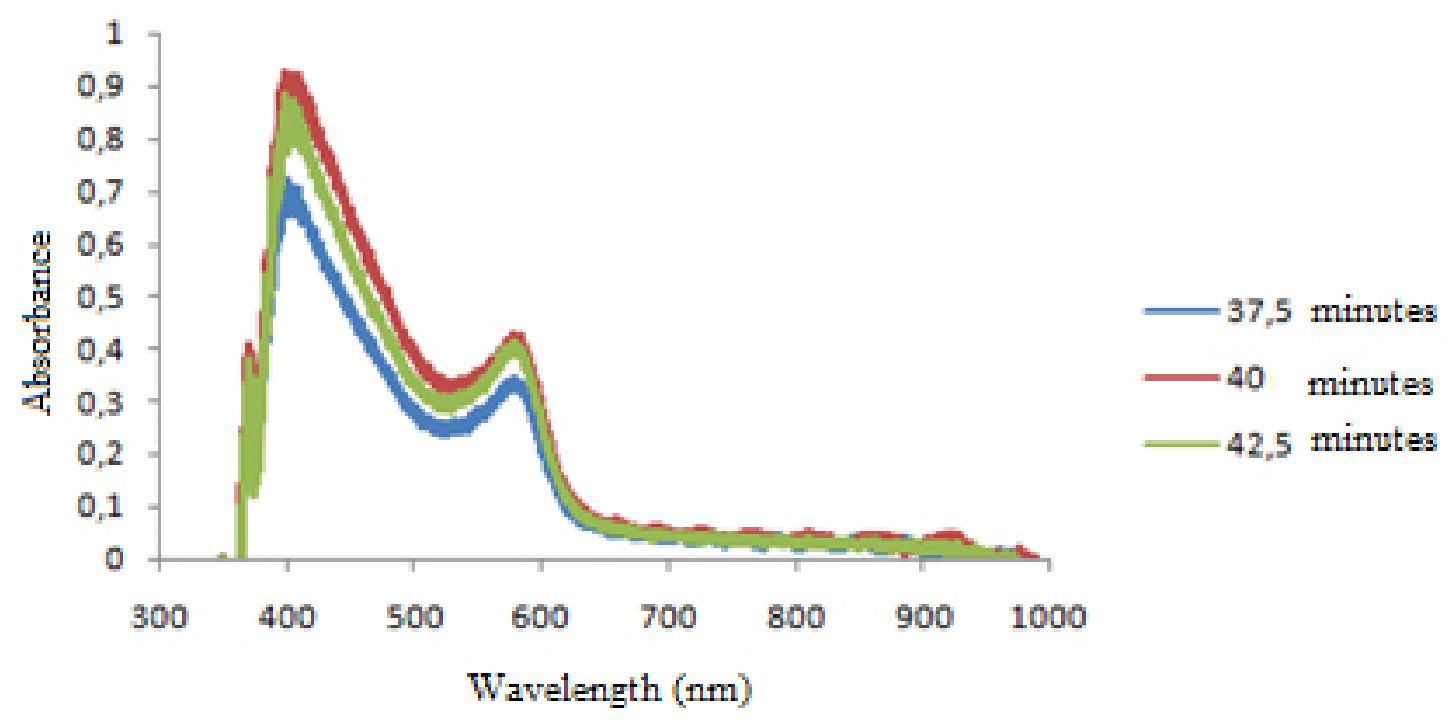

Fig. 6: Graph of relation between wavelengths and absorbances of thin films of polymer photoresist with mol ratio of formaldehyde and phenol equals to $2,8: 1$ in catalyst reaction during $37,5,40$, dan 42,5 minutes 


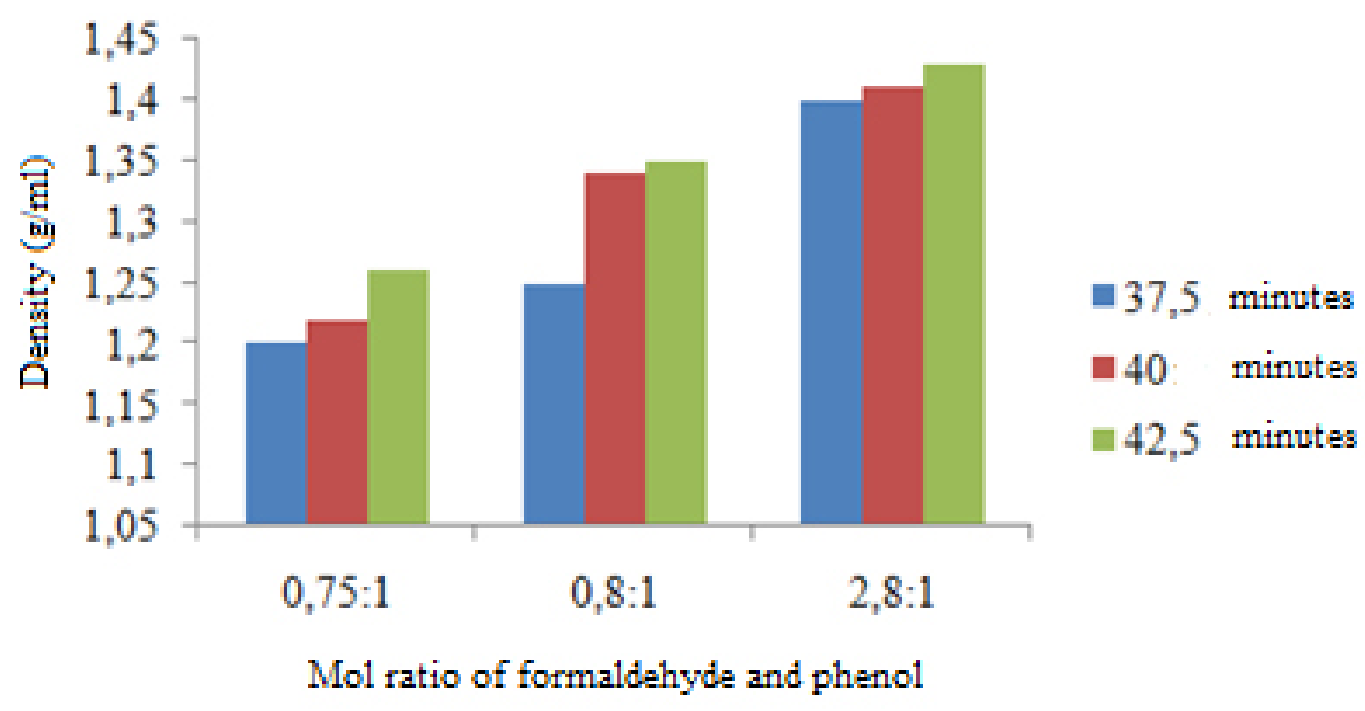

Fig. 7: The bar chart of photoresist density of three different mol ratio for $37,7,40$ and 42,5 minutes

Table 1: Viscosities of polymer photoresists manufactured of phenolic resin novolac

\begin{tabular}{lcc}
\hline $\begin{array}{l}\text { Read value on } \\
\text { viscosimeter }\end{array}$ & $\begin{array}{c}\text { Multiplier } \\
\text { factor }\end{array}$ & $\begin{array}{c}\text { Viscosities } \\
\text { (centipoise) }\end{array}$ \\
\hline 16 & 2 & 32 \\
16,5 & 2 & 33 \\
17 & 2 & 34 \\
\hline
\end{tabular}

Figures $4 \mathrm{a}$ and $4 \mathrm{~b}$. The longer reaction of catalyst leads to more homogeneous liquid. It is found that the photoresist thin films of resin phenolic resol have smoother and more homogeneous surface structures than those of resin phenolic novolac

The maximum absorbances of polymer photoresist range 380-500 nm as shown in Figure 5. The mol ratios of formaldehyde and phenol increase the absorbances increase as well. The relationship between reaction periods with absorbances is shown in Figure 6

In Figure 6 seems no relationship is found between reaction periods with absorbaces of resulted photoresist thin films.
Table 2: Viscosities of polymer photoresists of resin novolac resol

\begin{tabular}{lcc}
\hline $\begin{array}{l}\text { Read value on } \\
\text { viscosimeter }\end{array}$ & $\begin{array}{c}\text { Multiplier } \\
\text { factor }\end{array}$ & $\begin{array}{c}\text { Viscosities } \\
\text { (centipoise) }\end{array}$ \\
\hline 99,5 & 2 & 199 \\
99 & 2 & 198 \\
99,5 & 2 & 199 \\
\hline
\end{tabular}

In Figure 6 seems no relationship is found between reaction periods with absorbaces of resulted photoresist thin films. As the mol ratio of formaldehyde and phenol increases the density of photoresist increases as well. The maximum density of maunfactures photoresist achieves 1,43 g/ml. For comparison, Photoresist $\mathrm{S} 1800$ series, a commercial photoresist, have density of $1,02 \mathrm{~g} / \mathrm{ml}^{12}$. The data of measured density of manufactured photoresists are shown in Table 1.

Based on the Tables 1 and 2, the photoresist of resin novolac polymer has average viscosity of 33 centipoise and the polymer photoresist of resin phenolic resol has average viscosity of 198,6 centipoise. The samples which are measured their densities are of polymer photoresist with mol ratio 
of formaldehyde and phenol equals to $0,75: 1$. The used resin phenolic novolac is made of acidsulphate, formaldehyde and 4-tert butylphenol through mixing for 40 minutes. Based on the measurement results, the viscosity of polymer photoresist of resin phenolic resol is higher than that of resin phenolic novolac.

\section{CONCLUSION}

In conclusion, the increase of mol ratio of formaldehyde and phenol and the increase of catalyst reaction duration have made the surface structures of photoresists more homogeneous and smoother. The photoresist absorbances are not influenced by catalyst reaction duration. The thin film absorbances of resin phenolic resol are higher than those of resin novolac. The wavelength of maximum absorbances are in the range of 380-500 nm. The mol ratio of formaldehyde and phenol increases the photoresist absorbance increases as well. The density of photoresist of resin phenolic resol is higher than that of resin novolac.

\section{ACKNOWLEDGMENT}

This research was supported by Ministry of Research, Techology and Higher Education, Republic Indonesia through Hibah Bersaing (Competitive Grant).

\section{REFERENCES}

1. Rehab, A. Eur. Polym. J. 1998, 34, 18451855

2. Aronson, C.L.; Beloskur, D.; Frampton, I.S.; McKie, J.; Montbriand, P. Polym. Bul. 2004, 52, 409-419

3. Xi, H.; Liu, Q; Guo, S. Mater. Let. 2012, 80,72-74

4. Prabhu, V.M.; Sambasivan, S.; Fischer, D.; Sundberg, L.K.; Allen., R.D. Appl. Surf. Sci. 253, 2006, 1010-1014

5. Kim, Y.H.; An, E.S.; Park, S.Y., Lee, J.O.; Kim, J.H.; Song, B.K. J. Mol. Catal. B-Enzym. 2007, 44, 149-154

6. Saito, R. Ichinohe, Y.; Kudo, M. Appl. Surf. Sci. 1999, 142, 460-464

7. Benlarbi, M.; Blum, L.J.; Marquette, C.A.
Biosens. Bioelectron. 2012, 38220-225

8. Wang, M.; Yuan, Z.; Cheng, S.; Leitch, M.; Xu, C.C. J. Appl.Polym. Sci. 2010, 118, 1191-1197

9. Ku, H.; Jacobson, W.; Trada, M.; Cardona, F.; Rogers, D. J. Compos. Mater. 2008, 42, 2783

10. Sharma, M., Naik, A.A., Raghunathan, P., Eswaran, S.V., J. Chem. Sci. 2012, 124, 395-401

11. Feiring, A.E.; Crawford, M.K.; Farnham, W.B.; Feldman, J.; French, R.H.; Leffew, K.W.; Petrov, V.A.; Schadt III, F.L.;Wheland, R.C.; Zumsteg, F.C. J. Fluorine Chem. 2003, 122, $11-16$

12. O'Neill, F.T.; Sheridan, J.T. Optik 2002, 113, 391-404. 